\title{
Mediatization as an international humanitarian space forming factor
}

\author{
Olga Mironova ${ }^{1 *}$, Olesya Shestopalova ${ }^{2}$, Angelika Baicherova ${ }^{3}$, and Yuri Doroginin ${ }^{4}$ \\ ${ }^{1}$ Rostov State University of Economics (RSUE), B. Sadovaya Str, 69, Rostov-on-Don, 344002, \\ Russia \\ ${ }^{2}$ Southern Federal University, Academy of Psychology and Pedagogy, Dneprovskiy lane, 116/4, , \\ Rostov-on-Don, 344065, Russia \\ ${ }^{3}$ Stavropol State Agrarian University, Zootechnicheskiy lane, 12, Stavropol, 355017 Russia \\ ${ }^{4}$ Don State Technical University, Gagarin sq., 1, Rostov-on-Don, 344000, Russia
}

\begin{abstract}
The study is devoted to understanding the role of mediatization processes at the present stage of globalization, one of the displays of which is forming the international humanitarian space. In most researches, the process of mediatization is considered exclusively as a modern phenomenon and in many cases is equated with digitalization of mass media. The authors consider that this process has been intrinsic for culture since its genesis. However, in modern conditions it has a certain specificity, to studying of which this article is devoted. Summarizing various points of view on the mediatization concept and essence interpretation, the authors come to the conclusion that the process of mediatization is a fundamental process of mutual influence of the media on various public life spheres, including culture. This leads to mutual changes in both interacting parties and various social practices and methods of communication between representatives of various social groups and strata, and also within these groups and strata. In modern conditions, this process acts as an international humanitarian space forming factor. Being a various-vector process, mediatization leads to both integrating and disintegrating consequences. It acts as an ambiguous and contradictory phenomenon, which determines the need for its comprehensive research and in-depth study within the framework of social and economic sciences.
\end{abstract}

\section{Introduction}

Developing digital information technologies in the modern post-industrial society principally changes the role of the media, turning them into the most important source of information about the world around us. Digital mass media have both high speed and significant opportunities for wide spreading large pieces of information, which allows them to cover the entire globe with the broadcast of their information products, thereby creating a global media space. This process received the name mediatization in modern sources of scientific literature.

\footnotetext{
* Corresponding author: lady.sensey2010@yandex.ru
} 
The problem of theoretical understanding the phenomenon of mediatization was studied by such scientists as F. Krotz, P. Bennet, A. Kendall, J. McDougall, M. Zezulkova, B. van Driel, D. Sternadel, T. Pradekso, D. Setyabudi, R. Manalu, I. Ramos-Soler, J. B. Thompson, A. Hepp, S. Hajarvard, K. Lundby, R. Silverstone, G. V Vacku, Ya.A. Golubinov, R. A. Dukin, L. M. S. E. Lebedev, A. E. Kasatkina, N. I. Klishina, S. E. Stepanova, E. V. Fedorova, I. Khazanov, etc. Despite the wide coverage of the mediatization processes in scientific works and publicism, the works devoted to the problems of mediatization of humanitarian interaction between countries are currently practically not represented. In mediatization processes research, the question that in modern conditions these processes act as an international humanitarian space forming factor is not fully disclosed. Also, there is no unified clear interpretation of the "mediatization" concept, and the relations between mediatization processes and forming the humanitarian space on a planetary scale are underexplored.

In our opinion, only with emerging the mass communications one can talk that forming the humanitarian spaces of countries, inter-country associations and, ultimately, the international humanitarian space have begun. Mediatization encourages expanding the humanitarian space due to expanding the access to information about certain cultural events, a wide mass of people, emerging the opportunities to receive new knowledge through the remote educational technologies, and establishing humanitarian ties through social networks. Given the importance of mediatization in the information society, it is necessary to study its objective laws and features of its influence on the humanitarian space structure and speed and directions of its development. All of the abovementioned conditions actuality of the topic chosen for research.

\section{Materials and methods}

Mediatization as a process of implementing and steady growth of interaction between the media and society is a determining factor of influencing the social life and consciousness/mentality, the culture of individual countries and of the whole of humanity. That allows considering it as a factor that encourages forming the international humanitarian space

In the information society, the media is the most important communication channel, which allows them to actively influence the mass mentality forming and changing. Mediatization, at the present stage of developing the society, acquires a special humanistic meaning, reflecting the deep shifts in all spheres of human activity. Modern media affect both the society and each individual, whose existence and consciousness are formed under influence of the media industry products consumed by them in the process of communication and satisfaction of their interests [1]. This approach defines the concept of a media person who lives in the information flow and constantly extracts it from digital mass media using modern gadgets.

At present time, the concept of mediatization is acquiring an interdisciplinary character, which allows distinguishing in its structure the sociological, political, educational, humanitarian and other aspects. This allows interpreting the mediatization under conditions of forming the information society not just as emerging new digital media technologies or individual digital applications, but to expand the horizons of research on the interaction between society, culture, communications and media.

The methods and methodology of this study are conditioned by its problematics and are based on the results of theoretical and applied research formulated in works of Russian and foreign authors. The system approach, system analysis, and also the synthesis of the communicative, informational, institutional and resource approach were used as the basic methods. That allowed considering the process of mediatization, on the one hand, from the 
point of view of the systemic unity of its components, on the other hand, to present it as a factor and at the same time a certain result of the globalization and post-industrialization processes leading, in modern conditions, to the formation of the international humanitarian space. Therefore, the abovementioned made it possible to study the relationship between the processes of mediatization and the international humanitarian space forming in their inseparable integrity and mutual causality. Also, in the study conducted, such methods as the dialectical method, the method of unity of logical and historical, and classification, were used. For the purpose of studying the definitions of the concepts "mediation" and "mediatization" available in the scientific literature, the methodology of categorical and conceptual analysis was applied.

\section{Results}

In our opinion, mediatization as a process of implementing and steady growth of interaction between the media and society is a determining factor influencing the social life and consciousness/mentality, the culture of individual countries and of the whole humanity, which allows considering it as factor that encourages forming the international humanitarian space.

Being an institutional and communication process, mediatization is simultaneously an information and strategic resource for forming the international humanitarian space. This makes it necessary to apply a resource-strategic approach in the study of this process.

In our research, we will understand an informative-strategic resource as a complex of ICTs and the media that contribute to long-term strategic purposes achievement through the information channels usage. As noted above, under the influence of the postindustrialization and digitalization processes, the media space is also bearing significant transformational changes. New subjects are emerging in it, and they communicate through innovative channels of interaction. From J. R. R. Tolkien's eyesight, the nature of an event changes after its transfer to the public status, so it is the media that is the resource that can be used to change the status of certain events, while forming public opinion and changing the environment in the necessary direction [2].

In our opinion, one of the consequences of globalization processes and of forming global information society is detraditionalization, which is the transformation of traditions and their adaptation to new conditions. The main factor of detraditionalization in the information society is not physical strength, but economic, ideological, informational and cultural types of pressure. The processes of mediatization encourage forming an international humanitarian space in which traditions are "delocalized", and they are separated from fixed spatial and time-dependent frameworks. Therewith, constant movement of traditional patterns occurs not only from the "center" to the "periphery" of the world system, but also in the opposite direction [3].

Modern media are characterized by a strongly marked dualism, which consists in the fact that in the conditions of post-industrialization, the media appears simultaneously in two capacities: as a source of information and as a communication channel. Another feature of the media in the information age is their ability not only to display and reproduce the picture as a kind of objective reality, but also to provide a subjectivity to its perception. Moreover, modern mass media in many cases themselves form one or another picture of perception or a system of valuables, focusing on the demands and needs of one or another user audience. Mediatization becomes the main principle by which people construct their social and cultural world [4].

Rapid developing electronic digital resources on a global scale is, on the one hand, a factor in forming the international humanitarian space; on the other hand, can lead to its transformation and to splitting-up individuals within this space. The concept of 
"humanitarian space" has an integral cultural and philosophical character and includes a wide range of components, including people's knowledge, beliefs, arts, morals, laws, customs, abilities and habits. The levels of forming the international humanitarian space are shown in Figure 1.

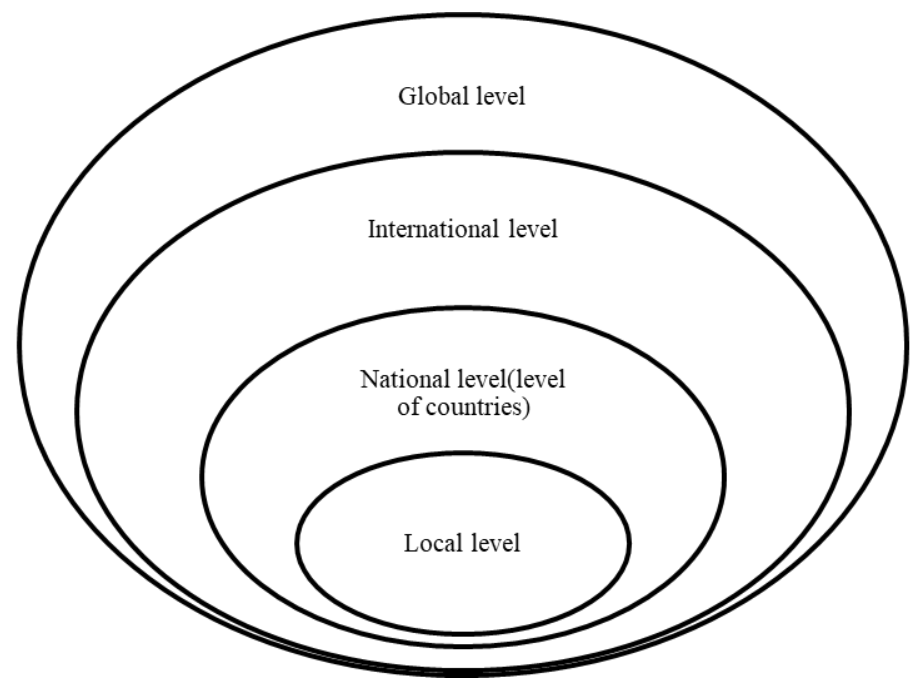

Fig. 1. Levels of forming the humanitarian space. Compiled by the authors.

We distinguish two main forms of influencing the mediatization processes on developing the international humanitarian space. On the one hand, it is the expansion of opportunities for interaction of individuals in the humanitarian space, caused by developing the information and communication technologies. On the other hand, we are now witnessing an active transferring, into the media space, various forms of education, cultural exchange, work and leisure, which previously existed mainly in the offline environment [5]. The pandemic of the new coronavirus infection has played a significant role in accelerating this process. Now we can communicate in social networks, study online, watch the musical and theater events and the entertainment shows on TV or on the Internet. Modern media make it possible emerging specific synthesized forms of leisure (e-sports, computer games, virtual tourism), which is un-realizable outside the media space [6]. Thus, the processes of mediatization generate shifts in the structure of international humanitarian space and modify its forms.

Modern media objectively have both positive and negative properties. So, if the possibilities of communication freedom, self-expression, creativity, accessibility, privacy, speed of interaction can be considered as their undoubtedly positive features, then for example, their orientation to the consumer with an average and even primitive level of requests, can be attributed to their negative sides. Modern mass media generally do not stimulate serious theoretical problems discussion. Even if the proposed discussion is presented to the viewer as a serious discussion in the field of politics, medicine, culture or ideology, such broadcasts are mainly of entertaining character. So, the numerous television talk shows position themselves as discussion platforms for representatives of the general public with participation of several experts of a more or less high competence level. However, in general, such programs are focused on the level of a "man in the street" and lower, which a priori excludes conducting a serious analysis of the issues discussed and identifying the causes and consequences of the problems that have become the subject of discussion. 
Another negative aspect that characterizes modern media functioning is, strange as it may appear, their disintegrating effect. Despite the fact that, it would seem, the media can be an instrument for social integration, they implement it, but on an artificially created platform, first isolating people, replacing live communication with the virtual one, and then uniting them in some virtual groups based on common valuables modeled by the media themselves.

One more disturbing feature of modern media is, figuratively speaking, the dissolution of the power structures in them, which, although not obvious, are still present in all spheres of society now covered by the media. The power invisibly invades any programs, including scientific and entertaining ones, and actually controls any information, which allows transforming its presentation not objectively, but in line with the interests of its representatives. Besides, the possibility of montage here plays a significant role, which in many cases allows creating an illusory image, perceived by users as objective reality.

\section{Discussion}

The concept of mediatization, at present time, has no unambiguous interpretation, although many researchers of this process tend to consider it as a broad implementation of the media and information culture into various spheres of human activity and public life, that encourages forming the unified cultural and communication system of society. In various studies devoted to this process, similar-sounding terms are used, sometimes with slightly different, and often critically different meanings: mediatization, mediation, medialization, mediazation, etc. So, in English, the word "mediated" has a synonym "intermediary" ("indirect"). In the case of the word "mediatized", the emphasis is shifted to an action, to the processual character of media communications.

The concept of "mediation", used in sociology, has a broader meaning than spreading the media communications. The term "mediation" became widely used in the field of media studies only in the 90 s of the twentieth century, although the mediating role of the mass media in social life was noted in the $50 \mathrm{~s}$ to 60 s of the last century by a Canadian scientist G. Innis and his student G. M. McLuhan. The latter considers that while media communication instruments use and the speed of their covering the consumer audience from different countries and regions is increasing, an "extension of man" occurs [7]. This term means extension/broadening possibilities of individuals interaction within the humanitarian space resulted from accelerating the mediatization processes. In modern conditions, given the increased role of the social media, which in the condition of the pandemic have become almost the only communication channel due to the inability to cross borders, the actuality of this approach is increasing.

While studying the processes of mediatization in advertising, Russian scientists Lebedeva S. E., Vakku G. V., Stepanova S. E., Kasatkina A. E. note that the simplest understanding of the media is that it is a means that changes communication. Developing the ICTs turns mediation into mediatization, which involves expanding the media functions, which no longer act as intermediaries, but as a factor in changing the form of relationships between individuals, and also between individuals and public institutions, including family, science, education, culture, advertising, the state, etc. This means that mediatization acts as a process of expanding the historical possibilities of people's communication. [8]

J. Potter and J. McDougall consider this process on the example of advertising, underlining the mutually dependent nature of its relationship with the media environment. [9] Advertising has a transformative effect on the media environment, since in market economy it turns not only into an element of the informational and emotional content of modern mass media, but also into an instrument for financing the media themselves. In the 
income structure of the media the lion's share falls namely on the advertising component. Simultaneously, the advertising largely depends on the media, so the advertising itself is subject to transformation as the latter develops. [10]

Summarizing various approaches to the definition of the "mediation "and" mediatization" concepts, we present some of them in Table 1.

Table 1. Theoretical understanding the concepts of "mediation" and " mediatization" [11-18]

\begin{tabular}{|l|l|l|}
\hline \multicolumn{1}{|c|}{ Author } & \multicolumn{1}{|c|}{ Term } & \multicolumn{1}{c|}{ Concept content } \\
\hline R.Silverstone & Mediation & $\begin{array}{l}\text { Mediation as dialectical process of involving } \\
\text { media communications into the circulation of } \\
\text { symbols in public life, in which the media not } \\
\text { only broadcast the information, but also } \\
\text { transform the environment and conditions for } \\
\text { their existence and further development. }\end{array}$ \\
\hline N. Couldry & Mediation & $\begin{array}{l}\text { Mediation as multi-vector, various-directional } \\
\text { trends in the media flows development. }\end{array}$ \\
\hline C. Wilson & Mediation & $\begin{array}{l}\text { Mediation as a result of existing in society the } \\
\text { two ideas which are fundamental for the } \\
\text { purpose of existing the media: existence of a } \\
\text { certain ruling center in society, and that } \\
\text { national and international central media, } \\
\text { connecting society with this center, act as a } \\
\text { translator of its interests. }\end{array}$ \\
\hline $\begin{array}{l}\text { P.Bennet, A. Kendall, } \\
\text { J. McDougall }\end{array}$ & Mediatization & $\begin{array}{l}\text { Mediatization as a process of changing the role } \\
\text { of mass communications in life of society in the } \\
\text { process of their development. }\end{array}$ \\
\hline F. Krotz & Mediatization & $\begin{array}{l}\text { Mediatization as a historical process of media } \\
\text { institutionalization. }\end{array}$ \\
\hline $\begin{array}{l}\text { A. Hepp, S. Hajarvard, } \\
\text { K. Lundby }\end{array}$ & Mediatization & $\begin{array}{l}\text { Mediatization as a process of growing } \\
\text { dependence of society on the media and their } \\
\text { logic. }\end{array}$ \\
\hline R. A. Dukin & Mediatization & $\begin{array}{l}\text { Mediatization as a process of forming a special } \\
\text { kind of social space }\end{array}$ \\
\hline Ya. A. Golubinov & $\begin{array}{l}\text { Mediation as a revolutionary process society } \\
\text { transformation through a powerful manipulative } \\
\text { influence on the mass consciousness of its } \\
\text { members }\end{array}$ \\
\hline
\end{tabular}

The term "mediation" in relation to media communications is used mainly by British scientists (N. Couldry, R. Silverstone). In the works of the continental Europe representatives, V. F. Krotz (Germany) and S. Hjarvard (Denmark), the term "mediatization" is used to determine the role of media in changes in society and to assess their impact on various processes and phenomena of economic and social life.

From the perspective of I. Ramos-Soler, C. López-Sánchez and T. Torrecillas-Lacave, mediatization is associated with the communication media development, due to which not only the dependence of society on the media, but also the degree of information mispresentation increases. [19]

F. Krotz considers mediatization as a process equal in significance to globalization, commercialization, and individualization. All these four metaprocesses, in F. Krotz'es opinion, form modern society and are the driving forces of its development. From his perspective, mediatization changes human society by creating new communicative opportunities for people, and this process of constructing a new social and cultural world is performed by people themselves, it is the man-made one [20]. 
According to the point of view of S. Hajarvard, mediatization is a process of increasing the dependence of society on the media and the results of their activities. This process has both positive and negative sides, it can declare itself at the macro and micro levels directly or indirectly. In the case of direct mediatization, the spheres of human activity that were previously not mediated by the media communications begin to be also "mediatized" through applying the digital information and communication technologies (ICTs): Internet banking, Internet games, etc. Opposed to the direct one, the indirect mediatization is less obvious and declares itself in growing media mechanisms influence on a certain type of human activity. According to Hajarvard, the process of mediatization is characterized by a various-vector orientation, therefore it is impossible to determine the exact direction of society development during this process.

A number of foreign researchers are against of considering mediatization as a conceptual phenomenon, grounding this by the fact that such an approach leads to artificial exaggerating the role of the media in the processes of society transformation and overestimating their significance in the conditions of socio-political and socio-economic changes [21]. This shifts the researchers' attention to superiority of media actors and leaves in the shade other factors that cause changes in life of society and public mentality [22]. A.Hepp identifies two concepts that characterize the mediatization process: media centrism, which is understood as a static consideration of media and society interaction, and media centrality as a systemic interaction of interconnected social forces with the intercrossing interests of society and media in dynamics. In his opinion, not in all cases it is the mass media that act as catalysts for changes in society. Moreover, there are situations in which the media, acting as driving forces of social transformation, encounter with resistance from the most inertial social strata. And this may become another direction in the studies of mediatization.

There are also two polar groups of opinions about what is the historical perspective of the mediatization development, or the phenomenon of what time this process is. The first group of researchers is prone to affirm that the process of mediatization was intrinsic for humanity from the moment of its genesis, to be exact, from the moment when the (intermediary) media instruments began to be used in communication between people. Other authors believe that mediatization is the result of Western society, economy and culture development over the past decades, calling Western society "media-saturated".

Studies of the mediatization phenomenon in Russia have been conducted since the $90 \mathrm{~s}$ of the twentieth century, when this term was first used in scientific literature by T. V. Andrianova and A. I. Rakitov. Initially, mediatization was understood as the forming the infrastructure that allows both individuals and society as a whole to receive access to the information benefits of post-industrial civilization.

Later, Russian scientists expressed different points of view regarding the essence and contents of this process. One group of researchers considers mediatization as a process of institutional intermediacy of the media while forming the specific social space. Others suggest considering mediatization not in a narrow sense, as a simple intermediacy, but more conceptually, taking into account the broadcasting character of the media, which allows forming ideological moods, emotions, and even subconscious expectations of citizens. Therewith, the media really act as intermediaries between information consumers and the part of society that is interested in spreading and capitalization of information of this particular content.

N. Klishina, while analyzing the processes of mediatization and comparing their impact on the development of culture as a whole and literature as its component, considers the evolution of understanding this process. She notes that initially this process was considered from the positions of quantitative characteristics. As a result of this approach, the mediatization essence was reduced to a simple increase in the number of mass media users, 
both traditional and electronic. It took place at the expense of increasing the interest of various population strata representatives in the content that the media broadcasted about events happening in the world. In this case, the functions of the media were limited only to information collecting, processing and transmission, and the word "media" was used as a synonym for mass media understood as the means of communication. [23]

Summarizing the results of the discussion on the use of the "mediation" and "mediatization" concepts in domestic and foreign literature, we can conclude that mediation is a narrower concept, meaning the process of any information transfer through the media from its producer to consumers. Mediatization should be considered more broadly as a fundamental process of mutual influence of the media on various spheres of public life, including culture, which leads to mutual changes of both the interacting parties and various social practices, and ways of communication between representatives of different social groups and strata, as well as within these groups and strata.

\section{Conclusion}

Thus, summarizing the results of the discussion and the study conducted by the authors allows drawing the following conclusions.

In the conditions of globalization and postindustrialization, the system of mass media is manifoldly complicated, which can be explained not only by significant diversity of modern media, but also by lack of a united centralized management of this system. The modern world is simultaneously global and fragmented. This is reflected both in the of the international humanitarian space specifics and in the peculiarities of the mediatization processes. In such conditions, both the population of individual countries and the whole humanity, at present time, does not have a united, objective and integral system of information that adequately reflects the real picture of the world. This leads to a decline in the legitimacy of the media, conditioned by the growing gap between the reputation of newsmakers and mass media users' expectations about how their work should be ideally organized.

The authors consider that the degree of confidence to one or another media can be determined by the following parameters:

- timely provision of information, which, in its turn, must answer the purposes of accuracy, objectivity and neutrality;

- the ability to provide direct contact and feedback between the government and citizens, and also the cultural communication between representatives of different social groups;

- quick response and providing citizens with information about the existing social problems and their solutions, comprehensive coverage of the various points of view on this issue, including the polar ones;

- performing educational functions, maintaining the moral values common to all mankind.

There is no doubt that globalization significantly expands the boundaries of communication between individuals, countries and nations to a planetary scale. It provides previously unthinkable opportunities for scientific cooperation, cultural interaction, and travels for tourists. It would seem that the result of the globalization processes should be continuous progress in all spheres of humanitarian life of society, such that humanity will reach a new, qualitatively higher level of education, science and culture development, mutual understanding and cooperation. However, this is not happening at present time, and uncontrolled globalization hides a lot of negative consequences. Among other things, this is the so-called "westernization", i.e., imposing the ideological, political and cultural standards of the western world on the whole globe and the loss of national identity. The 
consequence of this is the tendency to resist mass culture, preserve national identity, traditions and values, including the religious ones, in various ways, including the radical ones (anti-globalism, terrorism, etc.). These aspects of mediatization in the context of the forming the united international humanitarian space require serious and careful thought and are a direction for further studies.

\section{References}

1. J. McDougall, M. Zezulkova, B. van Driel, D. Sternade, NESET II report. Luxembourg: Publications Office of the European Union, 323-338, (2018) DOI: $10.2766 / 613204$

2. J.B. Thompson, The Media and Modernity. A Social Theory of the Media (2010)

3. Ilya Hazanov, Media Education, 60(4) (2020), DOI: 10.13187/me.2020.4.645

4. T. Pradekso, D. Setyabudi, R. Manalu, E3S Web of Conferences, 73, (2018) DOI: https://doi.org/10.1051/e3sconf/20187314015 14015

5. M.B. Flek, E.A. Ugnich, Lecture Notes in Networks and Systems, 155, 1659-1669 (2021). DOI: 10.1007/978-3-030-59126-7_181

6. E.V.Fyodorova, Bulletin of European Science, 3, 1-8 (2018)

7. M. McLuhan, Understanding Media: The Extensions of Man (London, 1994)

8. S. E. Lebedeva, G. V. Vakku, S. E. Stepanova, A. E. Kasatkina, Bulletin of ChGPU named after I. Ya. Yakovlev, 4(100), 69-76 (2018)

9. J. Potter, J. McDougall, Digital Media, Education and Culture: Theorising Third Space Literacy, 289 (2017)

10. J. McDougall, J. Potter, Curating media learning: Towards a porous expertise, 12 (2), 199-211 (2015)

11. R. Silverstone, European Journal of Communication, 19(1), 87-101 (2006)

12. N. Couldry, Media Rituals: A Critical Approach (2017)

13. C.Wilson, Media and Information Literacy: Challenges and Opportunities for the World of Education, 17 (2019)

14. P. Bennet, A. Kendall, J. McDougall, After The Media: Culture and Identity in the $21 \mathrm{st}$ Century, 272 (2011), DOI: 10.4324/9780203817889

15. F. Krotz, Global Media and Communication, 3(3), 256- 260 (2007)

16. A. Hepp, S. Hajarvard, K. Lundby, Media, Culture \& Society, 37(2), 314-324 (2015)

17. R.A.Dukin, Bulletin of NNGU named after N.I.Lobachevsky, 4 (40), 122-126 (2015)

18. Ya.A.Golubinov, Bulletin of Samara scientific centre of Russian Academy of Sciences, 17, 1(5), 1228-1231 (2015)

19. I. Ramos-Soler, C. López-Sánchez, T. Torrecillas-Lacave, Comunicar, 56,71-79 (2018)

20. P.M. Taranov, M.A. Taranov, Lecture Notes in Networks and Systems. 133, $597-609$ (2021). DOI: 10.1007/978-3-030-47458-4_69

21. J.McDougall, Media Studies, 10(19), 29-45 (2019), DOI: 10.20901/ms.10.19.2

22. M.Bulger, P.Davison, Data \& Society Research Institute, 33 (2018)

23. N.I.Klishina, The Russian language, 1, 66-73 (2014) 